\title{
Unicorn in Rainbow Park: A glance at young children's game design ideas
}

\author{
Pekka Mertala ${ }^{1}$ \\ University of Oulu, Finland
}

\section{Abstract}

In this study, 5-to7-year-old Finnish children were asked to show, by drawing a design, what would be "the best game in the world" for them. Data were analyzed through a framework of game design elements. Children were found to be keen to modify existing games by adding new things to them. Often these additions had their roots in other meaningful media texts. Thus, children's game ideas became collage-like representations of their lifeworld, which highlights the importance of the aesthetic element of game design (i.e. the emotional aspects of a gaming experience).

Keywords: Digital games, game literacy, game design, preschool, drawing

\section{Introduction}

Due the fast-paced digitization of (Western) societies, the question of how to integrate digital media into early childhood education (ECE) has become a topical subject in academic and practical discussions. Based on previous research (e.g. Blackwell, Lauricella \& Wartella, 2016; Falloon, 2013; Kjällander \& Moinian, 2014; Vangsnes, Økland \& Krumsvik, 2012), playing educational games to support different curriculum areas, i.e. literacy and mathematics, appears to be the most common scenario. Nonetheless, their successful integration is a tricky business. Kjällander and Moinian (2014) observed that when children do not find a game design interesting enough, they may rapidly discard the didactic designs of the gamemaker and teacher and transform the game into a more playful and exploratory form of action. In a study by Falloon (2013), only four out of 18 children were able to largely ignore potentially distracting content (such as responsive animations) and keep their focus on learning goals. It also seems that teacher mediation is not always enough to overcome these obstacles. In their study, Vangsnes et al. (2012) found that when a teacher tries to start a dialogue by asking questions in order to make children go more thoroughly into a matter, the children are concentrating too much on gameplay to pay attention to a teacher's meta-didactic 
intentions. The authors' conclusion was that children and teacher in a gaming situation have different agendas: the playing child has a perspective of playing the game, while the teacher has an educational perspective.

To sum up, in my interpretation, these examples reveal a mismatch between how children experience games and how games are integrated into ECE. The teachers in the aforementioned studies understood games as a medium to teach children something. However, for the children, the gameplay was meaningful for its own sake and according to their own rules; thus, they were not committed to the didactic designs of teachers or games. This disparity becomes more evident when attention is paid to the games children play at home: most games played by Finnish 0- to 8-yearold children in 2013 were Angry Birds and the games at LEGO.com (Suoninen, 2014). None of these games (there are dozens of games on Lego.com) are 'just a game', as they also exist as cartoons and movies. Besides playing games, children often talk about games and engage in game-related role plays (Aarsand, 2010). From this perspective, the idea of using games merely to deliver information is an insufficient starting point for pedagogical planning, and Buckingham and Burn (2007) have argued that teaching children about games as a cultural form is a necessary prerequisite for using games in order to teach other curriculum areas.

\section{Theoretical framework}

According to Buckingham and Burn (2007), learning about games can be understood as a development of functional and critical game literacy. Functional literacy includes basic hardware skills (i.e. the ability to load and save a game) and software skills (i.e. the ability to navigate around a game space). Critical literacy, in turn, refers to the ability to reflect critically on games, gameplay and game culture. One potential framework for (critical) game literacy education is to analyze their design elements which, based on Zichermann and Cunningham's (2011) description, consist of mechanics, dynamics and aesthetics. Mechanics is the functioning components of a game and these are controlled by the designer. The primary elements of mechanics are points, levels, leader boards, badges, challenges/ quests, on-boarding and engagement loops. Dynamics is the interaction between player and mechanisms, and aesthetics is the quality of the experiences and feelings the interaction creates (2011, 35-76). Buckingham and Burn (2007) emphasize the importance of also exploring games and gaming as a social phenomenon. According to Aarsand (2010), digital games that are good and cool have become objects of negotiation and, on the basis of their knowledge, children are sorted into different categories by their peers.

Mertala and Salomaa (2016) have suggested that these aspects could be addressed in ECE by asking children why they like certain games and when playing 
games is fun and when it is not via visual mediums, i.e. drawing and crafting. In this way, early childhood teachers can help children begin to recognize the connection between game structure (mechanics and dynamics) and its effect on children's emotions during and after gameplay (aesthetics). Grounding in the principles of contemporary childhood studies, visual methods, such as drawing, are understood to be both a form of narration and a supportive medium for spoken narration (Einarsdottir, Dockett \& Perry, 2009).

\section{Methodology}

Data for this study were collected from "The Best Game in the World" project carried out in collaboration with one preschool class consisting of 26 5- to 7-year-old children (17 boys, nine girls) in spring 2016. Teachers of the class had noticed that digital games were a frequent theme in what the children play, discuss and draw (see Aarsand, 2010) and had begun to think how they could take games (as a cultural form) into account within their teaching. I, as an "honorary preschooler" (I have regular collaborated with the teachers since 2013 and was familiar with the children as well), was invited to take part in the planning and implementation of the project.

As a first step, we thought it would be important to find out what things children find meaningful in games. To get this information, the children were asked, via drawing to design, what would be "the best game in the world" (see Mertala \& Salomaa, 2016). During and after drawing, the children were asked about the games they had designed (what the rules are, what needs to be done to play it, why it is a good game etc.). Questions about the games they play at home, and if they engage in role-plays with game-related themes, were asked in order to gather information about what types of gaming and game-related activities children find important and meaningful. Also, to get more information about the social nature of games, the children were asked if they could think of some other children who would like playing such games. These informal interviews were done by either the teacher or me. Children's narration and the spontaneous comments they made while drawing were written down on observation sheets containing interview themes (see Einarsdottir et al., 2009). The data consist of 27 drawings (one of the girls made two) and 26 interview sheets. Two (research) questions were asked regarding the data:

1. How are game design elements represented in the children's game-design ideas?

2. Why are these elements meaningful for the children?

The analysis process consists of two stages: first, theory-driven analysis was used to examine how different design elements - mechanics, dynamics and aesthetics (Zichermann \& Cunningham, 2011) - were represented in the pictures and narratives. Second, applying a more data-driven approach, the author tried to 
understand the origins of and motives for the children's game-design ideas. Extracts from the data are presented in the "Results" section to improve the reliability and clarity of the research.

\section{Results}

In order to represent the complexity of the narratives and ideas of individual children, the results section concentrates on the data produced by one of the girls, 6-yearold Alina ${ }^{2}$. She is what Patton (2002) describes as an informant-rich case: she was not only talkative, but her narration (both drawn and spoken) was rich in detail and included many of the themes and phenomena expressed by the other children too.

"This is called the Rainbow Park. One must find ice cream cones to keep moving. When they eat the cone, they can run really fast. They are like a kind of power stones. The girl is called Alexandra. She runs with a cat and a dog. The cat is called Miisa and the dog Mikko. The cat has the same name as my cat, because it looks a bit like her. If they find a rainbow, they can use it as a slide if they want. The unicorn is a fast runner, and if they want, they can ride with it. When they have reached the goal, they get ice cream cones. After they have eaten it, they fall asleep."

In these words, Alina described her "best game in the world", also in a drawing (Fig. 1). During the discussion, it became apparent that, while Alina plays digital games at home (i.e. Singstar with her father), Alina's game idea was inspired by a children's TV show, 'The Game Challenge', aired by the Finnish national broadcasting company, YLE. In Game Challenge, primary school-aged children design and programme games in small groups. During the discussion, Alina said that:

"I have watched the Game Challenge

Figure 1. Alina's drawing and a screenshot from Game Challenge.
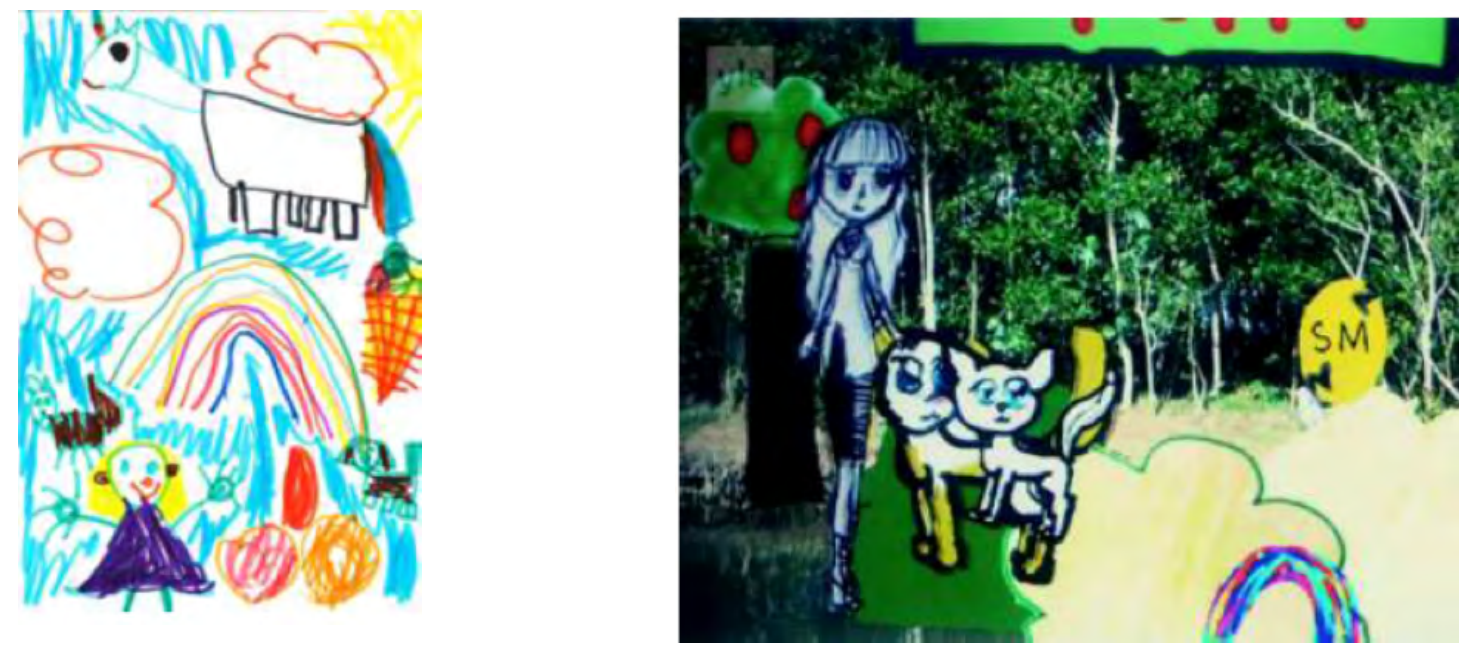

2 Alina is a pseudonym used to protect the identity of the participant. The name of the character, Alexandra, is also changed to correspond to the phonetics of real names. The cat's name has also been changed. 
many times. The one in which they

collect the rainbow stones is a nice Nonetheless, the similarities between the game ideas of Alina and Team Creepers were not straight reproductions but rather selected influences. Alina expressed being aware of this, as she found her own game idea to be "bit funnier" than the (at the time unfinished) game by Team Creepers. Alina gave the girl character a name (Alexandra), which had some resemblance to her own name. She also drew the girl as having blond hair, like hers. She also gave the cat the same name as her own cat, and she gave a name to the dog, too. The quest in Alina's game was to collect ice cream instead of rainbows. A rainbow was included in the game as an artefact that Alexandra and her cat and dog could use as a slide. The most significant difference, however, is the unicorn. It was not present in Team Creepers' game, but in Alina's drawing it is the largest figure. The reason for this became clear when Alina said:

"Unicorns are just my favourite things in the world! Sometimes, we play them with lina [sister] [for] so long that lina says, 'This is boring.' We have one unicorn, which has diamonds on it, and when it is pressed, its horn starts to glow."

Alina's interest in and affection for unicorns seems to have (at least partially) cultural media origins, as the toy unicorn she told me about is probably a unicorn called Rarity from My Little Pony.

Examples of mechanics in Alina's game were characters, challenges and rewards. In order to keep moving, Alexandra had to game. This is a bit funnier."

look for ice cream cones, which also helped her to move faster. Alina referred to them as 'kind of power stones'. Power-ups, which give players extra strength and power, are common elements in several games, e.g. in Super Mario game players can make Mario bigger and get extra lives by collecting magical mushrooms. Analysis of the dynamics represented in Alina's game idea revealed them to be quite open; while the ice cream cones were needed to stay in motion, nothing in Alina's narration implies that riding the unicorn or sliding down the rainbow would require, for example, that the player collect a certain amount of ice cream. In other words, in Alina's game idea, all the appealing elements were not only responsive but also easily accessible. Further, the mechanics Alina designed in Rainbow Park give the player a high degree of freedom. One could argue that, rather than an intentional choice, the openness of the dynamics is due to lack of competence in designing mechanics. I find this argument overly simplistic for two reasons: First, it is not that Alina's game idea had no mechanics, as there were, among others, rules (the need to collect cones to stay in motion) and rewards (the ability to move faster after eating a cone). Second, I understand Alina's comment 'This is a bit funnier' as referring to intentional modification.

Nonetheless, the importance of open dynamics in Rainbow Park is best explained when its meaning explored through the lens of aesthetics. The 
similarities between Alina's and Alexandra's names and hair colour imply that she identifies herself with the character (Mertala, Karikoski, Tähtinen \& Sarenius, 2016) and, as discussed earlier, Alina enjoys unicorns, which are a common theme in her plays. As one of the most important aspects of games for children is the imaginary worlds that allow children to do things that are not convincing in their everyday lives (Ermi \& Mäyrä, 2007), from an aesthetic perspective, the key element in Alina's game idea is that it allows her to do things she would otherwise not be able to do: riding a unicorn is not possible when playing with a small plastic figure, but the game is built around her (i.e. her physical appearance) and her favourite things; and the dynamics are designed in a way that causes no frustration. In other words, by understanding the engaging nature of digital games (Vangsnes et al., 2012), the aesthetic experience reflected in the game idea can be understood as pleasurable. Alina also named her sister and three friends (one was from preschool) as the ones who would like such a game, which implies that Alina would not be the only one.

\section{Conclusion}

While not generalizable, this small-scale study suggests that when young children are given a supportive and good-spirited forum to discuss digital games, they have a lot to say. All the participating children were willing to draw and design games as well as talk about them and (their own) game culture (i.e. game-related role plays). For example one of the boys had been sick on the first three data-collection days. When I researcher arrived on the fourth day, the first thing the boy did was to make sure that that day it would be his turn. This study focused on the data produced by a 6-yearold girl called Alina. Her game idea was a fascinating and complex tapestry of old and new, everyday life and fantasy, experiences and dreams. Also, the convergent nature of contemporary media culture, as discussed in the introduction, was apparent in Alina's game design: the idea was influenced by another game, yet Alina had not played that game, she had only seen it (and its design process) on television. And the appearance of the unicorn had at least, in part, cultural media roots, as Alina noted that she likes to play with a My Little Pony unicorn. It is evident that the complexity of games as a cultural form cannot be covered by the prevailing practice of using educational games as boosters for children's learning in other curriculum areas (e.g. Blackwell et al., 2016; Falloon, 2013; Kjällander \& Moinian, 2014).

From the perspective of game-design elements (Zichermann \& Cunningham, 2011), Alina's case suggests that, in terms of research and pedagogy, more could be done to consider the relationship between young children and the aesthetic dimension of games, gameplay and game culture. Even though Alina played commercial digital games, she was most impressed by an unfinished game made by children not much older than herself. This notion raises several questions for future studies to 
consider, including: what does it mean for children to observe how games are made, and what is added by the fact that the game designers observed are children? Nonetheless, if children's (own) culture and meaning-making with games (Aarsand, 2010) are taken as the viewpoint, the most interesting question (in my opinion) is if there are children who would find Alina's game as appealing as Alina found the one by Team Creepers. Alina herself thought so, and she named four other children that she believes would like to play such a game. As a father of a 4-year-old girl, who is really into unicorns (and definitely not against ice cream and rainbows, either), I could add one more to the list.

\section{Reference}

Aarsand, P. (2010). Young Boys Playing Digital Games. Nordic Journal of Digital Literacy, 5(1), 38-54

Blackwell, C. K., Lauricella, A. R., \& Wartella, E. (2016). The influence of TPACK contextual factors on early childhood educators' tablet computer use. Computers \& Education, 98, 57-69

Buckingham, D. \& Burn, A. (2007). Game literacy in theory and practice. Journal of Educational Multimedia and Hypermedia, 16(3), 323.

Einarsdottir, J., Dockett, S., \& Perry, B. (2009). Making meaning: Children's perspectives expressed through drawings. Early child development and care, 179(2), 217-232.

Ermi, L. \& Mäyrä, F. (2007). Fundamental components of the gameplay experience: Analysing immersion. In: S. De Castell \& J.
Jenson (Eds), Worlds in play: International perspectives on digital games research. NY: Peter Lang Publishing Inc., 37-53.

Falloon, G. (2013). What's going on behind the screens? Journal of Computer Assisted Learning, 30(4), 318-336.

Kjällander, S. \& Moinian, F. (2014). Digital tablets and applications in preschool Preschoolers' creative transformation of didactic design. Designs for learning, 7(1), 10-33.

Mertala, P., Karikoski, H., Tähtinen, L., \& Sarenius, V.-M. The Value of Toys: 6-8year-old children's toy preferences and functional analysis of popular toys. International Journal of Play, 5(1), 11-27.

Mertala, P. \& Salomaa, S. (2016). Kasvatuskeskeinen näkökulma varhaisvuosien mediakasvatukseen. In: L. Pekkala, S. Salomaa \& S. Spišák (Eds), Monimuotoinen mediakasvatus. Kansallisen audiovisuaalisen instituutin julkaisuja 1/2016, 154-155.

Patton, M.Q. (2002). Qualitative Research \& Evaluation Methods (3rd ed.). Beverly Hills, CA: Sage.

Suoninen, A. (2014). Mediabarometri 2014. 0-8-vuotiaiden mediankäyttö ja sen muutokset vuodesta 2010. Nuorisotutkimusverkosto / nuorisotutkimusseura julkaisuja 149. Helsinki: Unigrafia.

Vangsnes, V., Økland, N.T.G., \& Krumsvik, R. (2012). Computer games in pre-school settings: Didactical challenges when commercial educational computer games are implemented in kindergartens. Computers \& Education, 58(4), 1138-1148.

Zichermann, G. \& Cunningham, C. (2011). Gamification by design: Implementing game mechanics in web and mobile apps. O'Reilly Media, Inc. 